\title{
TEAM: Together Everyone Achieves More
}

\author{
Betty Caroline Tong, MD, MHS
}

\author{
From the Department of Surgery, Duke University Medical Center, Durham, NC. \\ Disclosures: Author has nothing to disclose with regard to commercial support. \\ Received for publication April 19, 2016; accepted for publication April 26, 2016. \\ Address for reprints: Betty Caroline Tong, MD, MHS, Duke University Medical Center, DUMC 3531, Durham, \\ NC 27710 (E-mail: betty.tong@duke.edu). \\ J Thorac Cardiovasc Surg 2016;152:317-8 \\ $0022-5223 / \$ 36.00$ \\ Copyright (c) 2016 by The American Association for Thoracic Surgery \\ http://dx.doi.org/10.1016/j.jtcvs.2016.04.080
}

Airway-enteric fistulas after esophageal resection, although rare, are among the most challenging complications faced by thoracic surgeons. Surgical repair of these fistulas is complex, even for the most experienced surgeon, and the literature on this treatment consists mainly of very small series and case reports. Even with repair, prognosis is poor, with $30 \%$ mortality in reported series. ${ }^{1}$ Morbidity results from several potential contributing factors: patients' underlying malnutrition and infection, a previously irradiated field, anastomotic leak, mediastinal lymphadenectomy, and recurrent malignancy. ${ }^{2-4}$ Without intervention, however, prognosis is equally poor, with death resulting from aspiration pneumonia and sepsis. Various combinations of covered tracheal or esophageal stents have been described, with some success. ${ }^{5}$ Achieving and maintaining fistula coverage with esophageal stents is often challenging, however; placement can be difficult because of location, and stents may migrate in larger conduits. ${ }^{6}$ With "kissing" stents in the airway and esophagus, there is also the theoretic risk of increasing the size of the fistula by necrosis as a result of the radial pressure exerted by apposed devices.

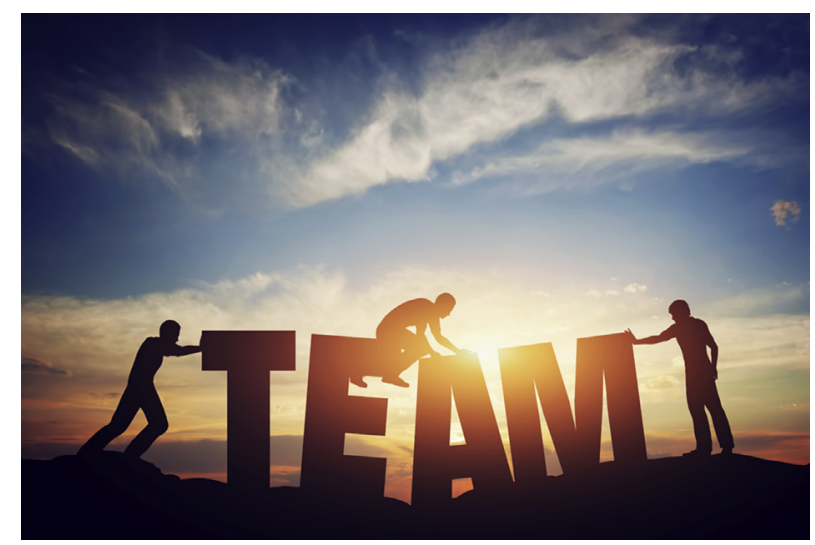

FIGURE 1. Multidisciplinary teams contribute to managing complex complications of esophagectomy.

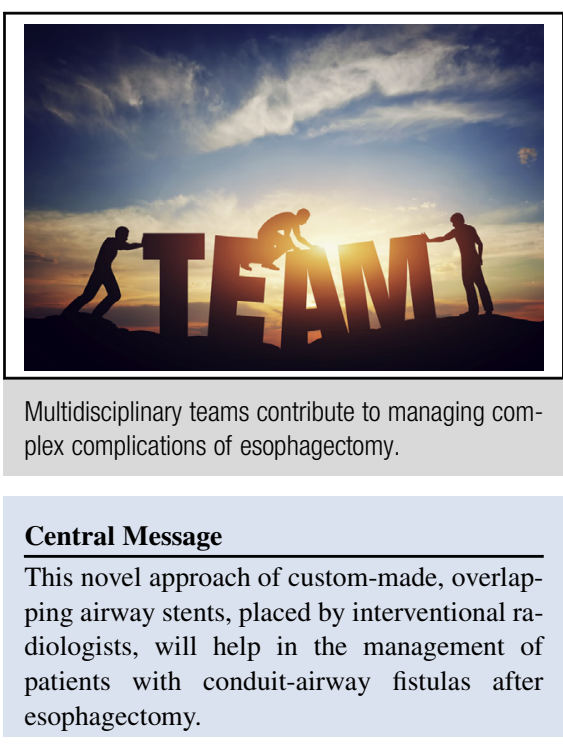

See Article page 557.

See Editorial Commentary page 564.

In this issue of The Journal, Li and colleagues ${ }^{7}$ present a series of 10 patients with proximal airway fistulas that were treated with 2 or more custom-made Y-shaped stents placed solely in the airway. This represents a novel approach in that the stents overlap in the airway to cover the defects fully, and there is no need for esophageal stent placement. The Y-shape of the stents allows for proper seating and helps to maintain suitable placement of the stents. Interestingly, these airway stents are custom manufactured and handknitted for each patient within 3 to 4 days on the basis of computed tomographic and bronchoscopic measurements.

Of note, $\mathrm{Li}$ and colleagues ${ }^{7}$ are not thoracic surgeons. They are members of the Department of Interventional Radiology at their institution, and they refer to themselves as the "chest intervention team." Remarkably, placement of the stents is achieved the patient under sedation rather than general anesthesia. This approach highlights the use of multidisciplinary care teams in treating these complex patients, thus avoiding additional surgery (Figure 1). Of the 10 patients treated, half died of disease recurrence during the follow-up period but none had a recurrence of coughing symptoms as before stent placement, and their median survival of 7.1 months compares favorably with other studies. This not only demonstrates good palliation 
of symptoms but also potentially represents improved quality of life (although not formally measured) for these unfortunate patients.

Placement of these combination Y-shaped airway stents for management of enteric-airway fistulas provides a useful and efficacious alternative to surgery for these complex and often severely ill patients. The challenge facing us now is generalizability: not only making the technology of these custom-fit stents available outside China but also providing the training and skills to thoracic teams worldwide so that others may benefit.

\section{References}

1. Yasuda T, Sugimura K, Yamasaki M, Miyata H, Motoori M, Yano M, et al. Ten cases of gastro-tracheobronchial fistula: a serious complication after esophagec- tomy and reconstruction using posterior mediastinal gastric tube. Dis Esophagus. 2012;25:687-93.

2. Bartels HE, Stein HJ, Siewert JR. Tracheobronchial lesions following oesophagectomy: prevalence, predisposing factors and outcome. Br J Surg. 1998;85: 403-6.

3. Heitmiller RF, Fischer A, Liddicoat JR. Cervical esophagogastric anastomosis: results following esophagectomy for carcinoma. Dis Esophagus. 1999;12:264-9.

4. Maruyama K, Motoyama S, Sato Y, Hayashi K, Usami S, Minamiya Y, et al Tracheobronchial lesions following esophagectomy: erosions, ulcers, and fistulae, and the predictive value of lymph node-related factors. World J Surg. 2009;33 778-84.

5. Boyd M, Rubio E. The utility of stenting in the treatment of airway gastric fistula after esophagectomy for esophageal cancer. J Bronchology Interv Pulmonol. 2012;19:232-6.

6. Meyerson SL, Mehta CK. Managing complications II: conduit failure and conduit airway fistulas. $J$ Thorac Dis. 2014;6(Suppl 3):S364-71.

7. Li TF, Duan XH, Han XW, Wu G, Ren JZ, Ren KW, et al. Application of combined-type Y-shaped covered metallic stents for the treatment of gastrotracheal fistulas and gastrobronchial fistulas. J Thorac Cardiovasc Surg. 2016;152 557-63.

Access to The Journal of Thoracic and Cardiovascular Surgery Online is reserved for print subscribers!

Full-text access to The Journal of Thoracic and Cardiovascular Surgery Online is available for all print subscribers. To activate your individual online subscription, please visit The Journal of Thoracic and Cardiovascular Surgery Online, point your browser to http://www.mosby.com/jtcvs, follow the prompts to activate your online access, and follow the instructions. To activate your account, you will need your subscriber account number, which you can find on your mailing label (note: the number of digits in your subscriber account number varies from 6 to 10 ). See the example below in which the subscriber account number has been circled:

\section{Sample mailing label}

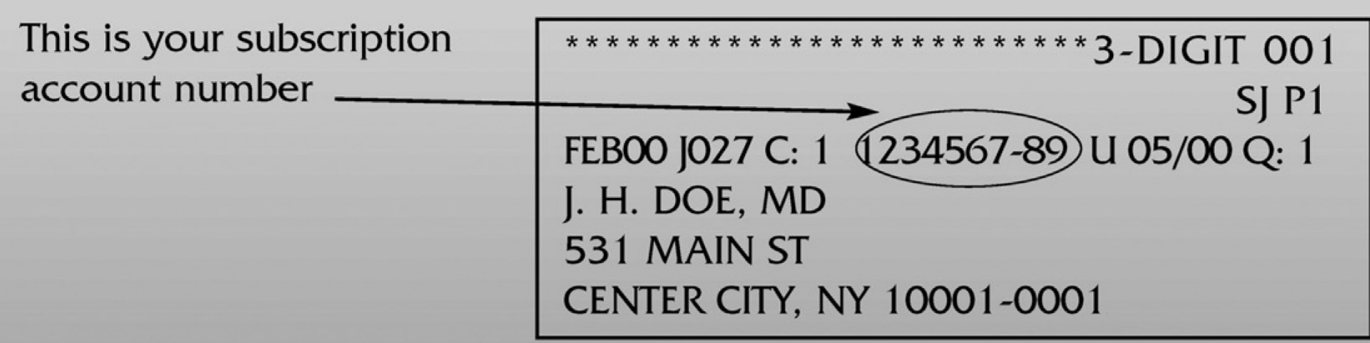

Personal subscriptions to The Journal of Thoracic and Cardiovascular Surgery Online are for individual use only and may not be transferred. Use of The Journal of Thoracic and Cardiovascular Surgery Online is subject to agreement to the terms and conditions as indicated online. 